Supplemental information for:

\title{
Photochromic Dithienylethene Derivatives Containing Ru(II) or Os(II) Metal Units. Sensitized Photocyclization from a Triplet State
}

\author{
Ron T.F. Jukes, ${ }^{\S}$ Vincenzo Adamo, ${ }^{\ddagger}$ František Hartl, ${ }^{\S}$ Peter Belser, ${ }^{\ddagger}$ and Luisa De \\ Cola $^{\S \#^{*}}$
}

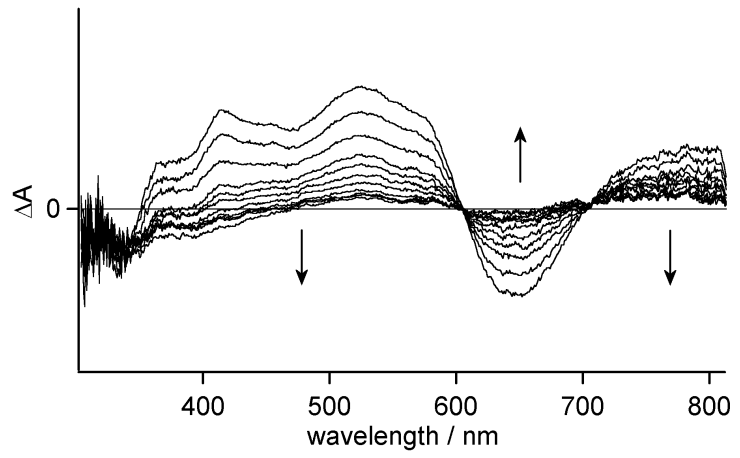

Figure S1 Transient absorption difference spectrum of $\mathbf{R u}(\mu-1 \mathbf{c}) \mathbf{R u}$, employing a stepsize of 3 ns between frames. Conditions: $\mathrm{MeCN}$, air-equilibrated solution, $293 \mathrm{~K}$, irradiation with $450 \mathrm{~nm}$ light.

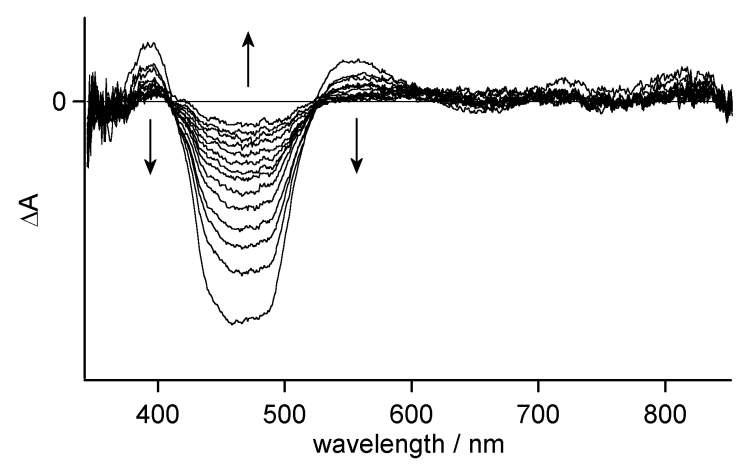

Figure S2 Transient absorption difference spectrum of $\mathbf{O s ( \mu - 1 0 ) O s , ~ e m p l o y i n g ~ a ~ s t e p s i z e ~ o f ~}$ $10 \mathrm{~ns}$ between frames. Conditions: $\mathrm{MeCN}$, deaerated solution, $293 \mathrm{~K}$, irradiation with $450 \mathrm{~nm}$ light. 


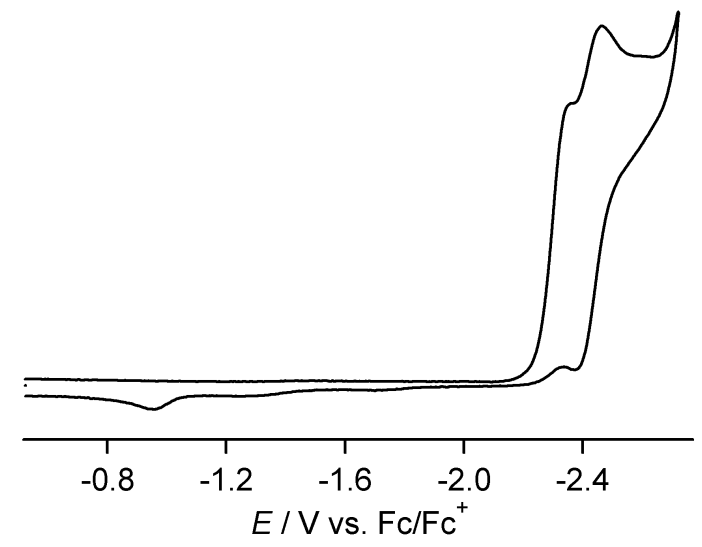

Figure S3 Cyclic voltammogram of compound 4. Conditions: MeCN, 293 K, Pt disc microelectrode, $v=100 \mathrm{mV} \mathrm{s}^{-1}$.

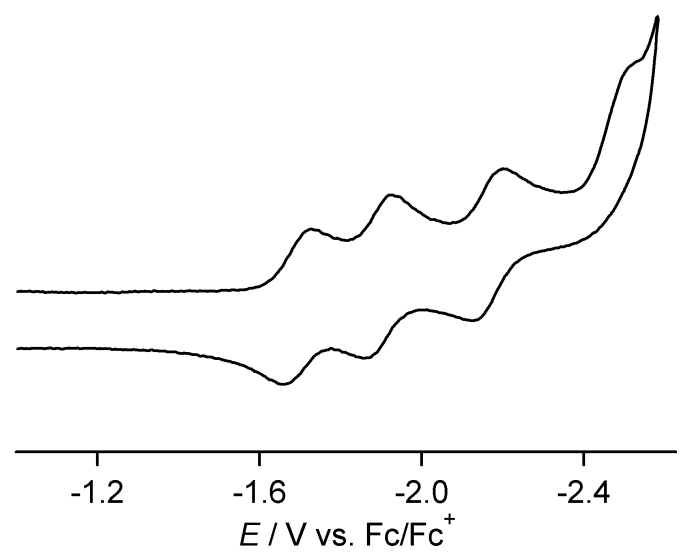

Figure S4 Cyclic voltammogram of complex Ru(4). Conditions: MeCN, $293 \mathrm{~K}$, Pt disc microelectrode, $v=100 \mathrm{mV} \mathrm{s}^{-1}$. 